\title{
Pancreatitis enfisematosa*
}

Dra. STEPHANIE GARCÍA T. ${ }^{1}$, Ints. EDUARDO MIRANDA R. ${ }^{2}$, MARIO OCAMPO B. ${ }^{2}$, LORETO MEDINA M. ${ }^{2}$, DANIELA ORELLANA R. ${ }^{2}$, Dra. FABIOLA VARGAS P. ${ }^{3}$

1 Servicio de Urgencia Clínica Dávila.

2 Interno Facultad de Medicina Universidad de Chile.

3 Becada de Radiología Facultad de Medicina Universidad de Chile. Santiago, Chile

\section{Emphysematous pancreatitis}

Hombre 71 años, hipertenso, consulta por 4 días de dolor abdominal difuso e inespecífico, vómitos, sensación febril, polidipsia y poliuria. Al examen: dolor abdominal difuso, sin signos de irritación peritoneal, ruidos hidroaéreos conservados. Destaca amilasa 227 , bilirrubina total de $2,8 \mathrm{mg} / \mathrm{dl}$, bilirrubina directa $1,1 \mathrm{mg} / \mathrm{dl}$, glicemia $755 \mathrm{mg} / \mathrm{dl}$, creatinina $1,5 \mathrm{mg} / \mathrm{dl}$, nitrógeno ureico $48 \mathrm{mg} / \mathrm{dl}$; hemograma, PCR, perfil hepático normal. Los hallazgos de la tomografia computada (TC) se observan en la Figura 1.
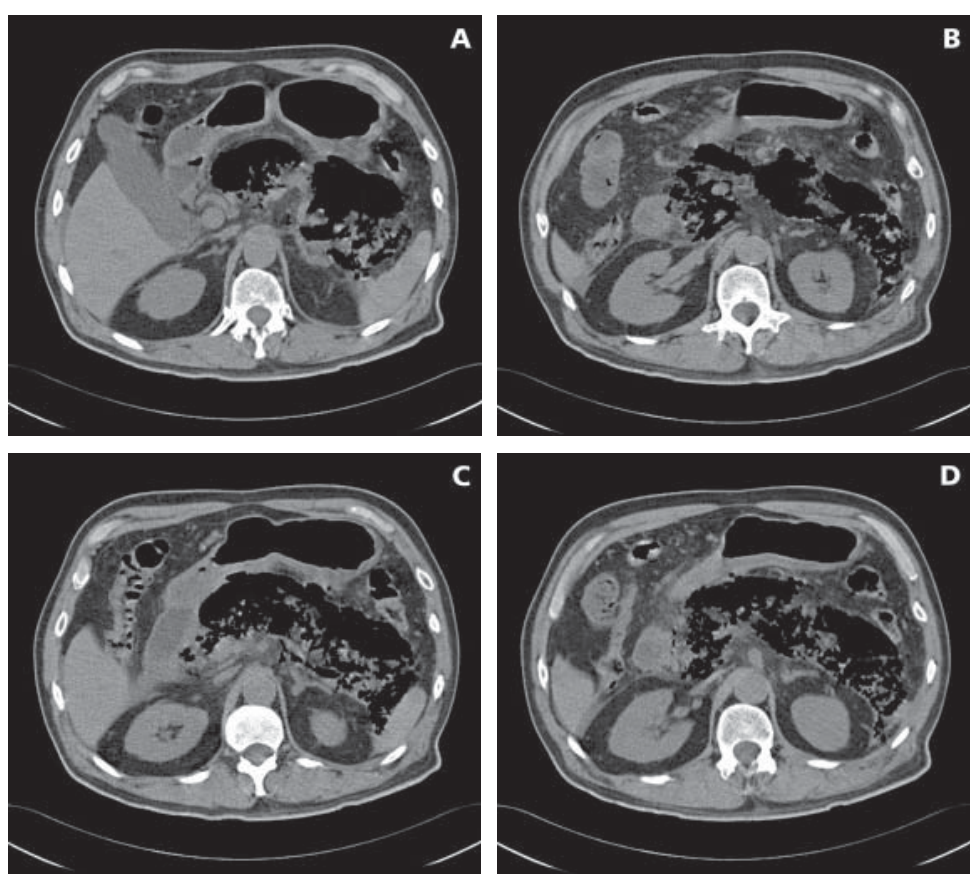

Figura 1. (A,B,C,D). Reabsorción del parénquima pancreático y peripancreático, el que es reemplazado por bulas de gas que alcanzan el espacio pararrenal, periduodenal y retrogástrico.

*Recibido el 26 de Agosto de 2010 y aceptado para publicación el 27 de Septiembre de 2010.

Correspondencia: Int. Eduardo Miranda R.

Huérfanos 3255, Santiago, Chile.

E-mail: eduardo.miranda.rodriguez@gmail.com 
Es sometido a cirugía, describiéndose líquido libre turbio no fétido, cabeza pancreática aumentada de tamaño, cuerpo y cola con tejido necrótico, grasa peripancreática no viable, gas abundante en transcavidad de los epiplones. Se realiza pancreatostomía, necrosectomía y aseo quirúrgico. Cursa con compromiso hemodinámico progresivo e irreversible falleciendo luego de unos días.

\section{Discusión}

La pancreatitis edematosa es una variante rara de una pancreatitis aguda severa, caracterizándose por aire en este órgano, producido por bacterias anaerobias. La clínica es inespecífica. Se describe hiperglicemia y antecedentes de enfermedad ateromatosa sistémica ${ }^{1}$. Se clasifica en: primarias ( $\sin$ manipulaciones instrumentales o enfermedades subyacentes), o secundarias (tras la realización de biopsias pancreáticas).

La TC es altamente sensible y específica para demostrar ocupación por gas retroperitoneal (GRP), además de evaluar la presencia de colecciones pan- creáticas y aerobilia, siendo el examen imagenológico de elección ${ }^{2}$.

La presencia de gas en cantidad moderada en la radiografía de abdomen simple no es específica de $\mathrm{PE}^{3}$.

Ante la presencia de GRP en una pancreatitis, debe tratarse con antibióticos, drenaje percutáneo de colecciones pancreáticas y manejo quirúrgico expectante ${ }^{4}$.

\section{Referencias}

1. Šileikis A, Beiša V, Dementavičienė J, Tamošiūnas A. Three cases of emphysematous necrotizing pancreatitis treated by different methods. Acta Medica Lituanica 2007; 14: 108-110.

2. Kushaljit SS, Anupam L. Emphysemtous pyelonephritis with empysematous pancreatitis. The Journal of Emergency Medicine 2008; 20: 30.

3. Grayson DE, Abbott RM,Levy AD, Sherman PM. Emphysematous infections of the abdomen and pelvis: a pictorial review. Radiographics 2002; 22: 543-561.

4. Bazan HA, Kim U. Emphysematous Pancreatitis. N Engl J Med 2003; 25: e25. 